\title{
Wisata Edukasi Kampus Melalui Pelatihan Pengamatan Burung Untuk Siswa Sekolah Menengah Atas
}

\author{
EduTourism in the College Through Bird Watch Training for Senior High School Students \\ Rio Christy Handziko
}

Jurusan Pendidikan Biologi, FMIPA, UNY, Email: handziko@uny.ac.id

\begin{abstract}
Abstrak
Tujuan kegiatan ini adalah untuk merancang kegiatan wisata pendidikan berbasis pada ekosistem. Ekosistem yang dijadikan tempat untuk belajar adalah ekosistem kampus. Kegiatan ini melibatkan 30 siswa dari 3 sekolah berbeda sebagai peserta, dengan objek pengamatan adalah burung dan habitatnya. Kegiatan wisata pendidikan ini terbagi menjadi dua kegiatan yaitu kegiatan pengenalan nilai penting burung dalam ekosistem dan kegiatan pengamatan burung dan habitatnya. Kegiatan ini lalu dimintakan tanggapan dan respon dari siswa peserta kegiatan. Tanggapannya meliputi aspek kemenarikan kegiatan, kemanfaatan kegiatan, ketepatan waktu dan lokasi kegiatan, dan kepemanduan wisata. Hasil review dari 30 siswa tersebut menyebutkan bahwa dari 4 aspek yang dimintakan respon dan tanggapan, mendapatkan hasil rata rata diatas 3 untuk semua aspek. Hasil tersebut menunjukan bahwa kegiatan wisata pendidikan di kampus FMIPA UNY tentang burung dan habitatnya mampu diterima dengan baik oleh siswa dan dapat digunakan sebagai alternatif pembelajaran lingkungan serta menjadi cara baru kegiatan wisata siswa SMA.
\end{abstract}

Kata kunci: wisata pendidikan, Pengamatan Burung, Ekosistem

\begin{abstract}
The purpose of this activity is to design edu-tourism activities based on the ecosystem, which is in campus. This eco-edu-tourism activity involves 30 students from three different schools as participants with the objects of observations is birds and its habitats in campus area. This activities is divided into two activities. First, the introduction of the importance value of birds in ecosystem and second is bird watching activities and its habitats. After that, students should give responses about the bird watching as the eco-edu-tourism activity. Responses include aspects of the activity attractiveness, the benefit of activities, timing and location of activities and also tourism guiding. The results of 30 students review, got the average number above 3 for all aspects. The results showed that the eco-edutourism activities of birds and their habitats in Yogyakarta States University is well received by students and can be used as an alternative for environmental education as well as a new way of tourist activities high school students.
\end{abstract}

Key words: edu-tourism, Bird Watch, ecosystem

\section{PENDAHULUAN}

Sekolah Menengah Atas, seringkali memiliki sebuah program wisata pendidikan ke luar kota. Hal tersebut menjadi sebuah program kerja rutin pertahun dari banyak sekolah. Program wisata pendidikan ini lazim disebut dengan Study Tour. Yogyakarta adalah kota yang seringkali menjadi destinasi wisata untuk wisata pendidikan dari pelbagai sekolah dari luar kota. Harapan dari sekolah yang datang berkunjung ke Yogyakarta, salah satunya adalah untuk memberikan gambaran pada siswanya tentang kampus dan dinamika perkuliahan. Sekolah memiliki harapan untuk semua siswanya mampu melanjutkan pembelajaran ke jenjang yang lebih tinggi seperti universitas, sekolah tinggi ataupun akademi. Lebih jauh, sekolah memiliki harapan besar untuk siswanya dapat 
melanjutkan study ke perguruan tinggi negeri.

Wisata pendidikan umumnya dilakukan dengan mengadakan kunjungan ke universitas negeri terpilih sesuia dengan yang direncanakan. Umumnya, format acara wisata pendidikan ini adalah stadium general dengan mengumpulkan siswa dalam satu ruangan untuk kemudian mendengarkan penyampaian dari perwakilan universitas. Model acara seperti itu dirasakan oleh beberapa guru dan kepala sekolah, tidak cukup memberikan gambaran aktivitas perkuliahan. Hal tersebut menjadikan guru dan kepala sekolah menginginkan adanya suatu aktivitas baru yang mampu memberikan sebuah pengetahuan baru dan keterampilan baru untuk siswa yang mengikuti wisata pendidikan.

Biologi sebagai salah satu jurusan ilmu alam mencoba untuk memenuhi keinginan guru dan kepala sekolah tentang kegiatan wisata pendidikan di kampus dengan menyelenggarakan kegiatan pengamatan terhadap objek dan fenomena biologi. Tujuan dari aktivitas ini adalah memberikan siswa untuk mengenal objek dan mengetahui tentang proses fenomena yang terjadi. Fenomena yang paling sering mendapat sorotan adalah tentang permasalahan lingkungan dewasa ini jumlahnya kian meningkat. Hal yang mendasarinya adalah pada kesadaran masyarakat terhadap lingkungan, belum terbangun dengan baik. Kesadaran seseorang terhadap sesuatu akan terbangun jika orang itu sudah mengenal sesuatu tersebut dengan baik. Pola tersebut mengindikasikan bahwa kesadaran lingkungan suatu masyarakat belum terbangun dengan baik karena masyarakat tersebut belum cukup mengenal komponen lingkungannya.

Sebagai bagian dari ekosistem, lingkungan hidup disusun dari komponen biotik dan abiotik yang saling berhubungan satu sama lain. Dengan mengenali komponen penyusun lingkungan hidup, harapannya kesadaran masyarakat akan terbangun dengan baik. Kesadaran yang terbangun secara simultan harapannya akan menjadi sebuah pola perilaku dan kemudian melekat menjadi sebuah karakter diri dari masyarakat tersebut.

Pendidikan lingkungan menjadi tanggung jawab segenap masyarakat, namun pengajar biologi dan pemerhati lingkungan hidup menjadi garda terdepan dalam penyelanggaraan pembelajaran ini. Siswa sekolah menjadi sasaran yang tepat dalam pembelajaran ini karena harapannya adalah siswa inilah yang nantinya akan menyebarluaskan hasil pembelajaran lingkungan hidup kepada masyarakat dilingkungannya masing-masing.

Siswa yang mengikuti pendidikan lingkungan hidup akan dikenalkan dengan komponen penyusun lingkungan dan diberikan pengetahuan tentang nilai penting dari penyusun ekosistem tersebut. Harapannya jika siswa sudah memiliki pengetahuan tentang hal tersebut maka kesadaran lingkungannya akan terbentuk. Pembelajaran yang simultan akan membentuk pola kesadaran lingkungan dari siswa yang mengikuti pendidikan lingkungan akan terbentuk menjadi sebuah pola perilaku. Perilaku inilah yang kemudian akan membentuk sebuah karakter dari siswa tersebut. Inilah yang disebut dengan siswa berkarakter lingkungan hidup. Untuk menyelenggarakan pendidikan lingkungan hidup, maka pembelajarannya sebaiknya disesuaikan dengan jenjang sekolah siswa. Materi yang dibawakan juga sebaiknya diangkat dari lingkungan sekitar sekolah, sehingga rasa kepemilikan siswa terhadap objek dalam materi akan terbangun dan siswa merasa bahwa pembelajaran tersebut benar-benar melibatkan dirinya sehingga menghasilkan pembelajaran menjadi lebih bermakna. Salah satu yang apat diupayakan untuk dapat membangun rasa keterlibatan siswa dalam pembelajaran adalah dengan membuat media pembelajaran yang berisi konten lokal yang representatif untuk proses pembelajaran.

Dalam pembelajaran lingkungan, siswa akan memiliki pengalaman yang nyata 
jika mampu berinteraksi langsung dengan objek pembelajarannya sehingga mengajak siswa turun ke lapangan menjadi satu alternatif pembelajaran yang baik yang harapannya juga akan meningkatkan keterlibatan siswa dalam pembelajaran yang kemudian harapannya adalah meningkatkan hasil belajar siswa yang terindikasikan dengan siswa yang memiliki daya retensi yang lebih tinggi.

Kampus Universitas Negeri

Yogyakarta terutama di Jurusan Pendidikan Biologi, Fakultas Matematika dan Ilmu Pengetahuan Alam, memiliki area belajar berupa kebun biologi dan laboratorium biologi. Dikedua area tersebut, banyak dengan sengaja ditanam tumbuh-tumbuhan yang diperlukan sebagai bahan penunjang perkuliahan biologi. Tumbuh-tumbuhan ini kemudian berkembang menjadi tempat tinggal beberapa jenis burung. Tercatat ada lebih dari 10 jenis burung yang menjadikan kebun biologi dan area laboratorium biologi sebagai habitatnya. Beragamnya jenis burung yang tinggal di lingkungan FMIPA UNY ini sangat baik menjadi sumber pembelajaran. Beberapa persoalan biologi mampu diangkat sebagai materi pembelajaran menilik dari ketersediaan sumber belajar yang tersedia.

Keadaannya dilapangan, masih sedikit sekali dosen ataupun mahasiswa yang menggunakan kebun biologi ataupun laboratoium biologi sebagai sumber belajar. Keberadaan kebun biologi dan laboratorium biologi serta keberagaman burung di lingkungan kampus F.MIPA UNY masih belum optimal. Burung dengan peran dan fungsinya dalam sistem ekologis juga masih belum banyak diungkap oleh mahasiswa ataupun siswa. Hal tersebut menjadi salah satu alasan yang mendasari adanya program pengabdian dosen yang ditujukan untuk siswa agar siswa memiliki keterampilan dalam mengamati burung yang korelasinya dengan materi ilmu lingkungan disekolahnya.

Pelatihan pengamatan burung yang akan dilaksanakan di lingkungan kampus F.MIPA UNY juga dapat menjadi langkah awal dari pengabdian kampus terutama jurdik biologi sebagai pusat pembelajaran lingkungan untuk masyarakat. Kampus menjadi pusat pembelajaran masyarakat dapat diawali dengan kampus sebagai lokasi pembelajaran lapangan untuk siswa SMA. Harapan kedepannya, sinergitas antara dosen, mahasiswa akan melakukan pemetaan potensi pembelajaran sehingga dapat dihasilkan satu peta potensi yang berisi topik pembelajaran. Peta potensi tersebut dapat dipublikasikan kepada seluruh elemen masyarakat terutama sekolah, sehingga lingkungan kampus F.MIPA UNY mampu menjadi satu destinasi wisata edukasi (edutourism) untuk siswa sekolah diberbagai jenjang.

Pola sinergitas antara dosen dengan mahasiswa untuk dapat melakukan pembelajaran kepada segenap lapisan masyarakat dapat menjadi sebuah kegiatan pembelajaran yang baik. hal itu sesuai dengan misi UNY, yaitu menyelenggarakan kegiatan pengabdian dan pemberdayaan masyarakat yang mendorong pengembangan potensi manusia, masyarakat, dan alam untuk mewujudkan kesejahteraan masyarakat. Maka harapan program pengabdian ini adalah siswa SMA dapat mengembangkan potensinya terutama dalam hal lingkungan hidup dan berkontribusi pada pendidikan, kelestarian alam dan masyarakat sekitar.

Tujuan dari PPM ini adalah:

1. Melatih siswa melakukan pengamatan burung di lingkungan kampus UNY.

2. Melatih siswa menggunakan panduan lapangan elektronik selama pengamatan burung di lingkungan kampus UNY.

3. Luaran berupa laporan hasil pengamatan habitat dan identifikasi jenis burung yang diketemukan selama pengamatan di lingkungan kampus UNY.

\section{SOLUSI/TEKNOLOGI}

Keanekaragaman hayati di lingkungan kampus F.MIPA cukup tinggi. Potensinya sebagai sumber belajar juga cukup baik. Keberadaan potensi 
keanekaragaman hayati tersebut belum teroptimalkan penggunaannya untuk pembelajaran. Dibutuhkan pemetaan potensi pembelajaran secara bertahap untuk nantinya keberadaan keanekaragaman hayati mampu teroptimalkan untuk pembelajaran dan wisata edukasi.

Harapannya dengan adanya wisata edukasi maka keberadaan kampus dapat teroptimalkan menjadi sebuah pusat pembelajaran. Dilangsungkannya pembelajaran, diharapkan dapat menjadi tempat untuk menyelesaikan permasalahan yang berkembang di masyarakat. Salah satu yang dapat diangkat pada keanekaragaman hayati di lingkungan FMIPA UNY adalah keanekaragaman burung.

Burung memiliki nilai penting lingkungan yang cukup tinggi. Mempelajari burung termasuk dalam pendidikan lingkungan hidup. Harapannya dengan mengenal ekosistem burung lebih dalam maka peserta didik akan memiliki pemahaman yang lebih baik tentang lingkungan hidup. Proses pendidikan lingkungan dapat menjadi sebuah ajang wisata dengan hasil kegiatan berupa bertambahnya pengetahuan baru. Proses wisata edukasi ini dapat difokuskan pada siswa sekolah menengah atas dengan harapan siswa tersebut akan memiliki ketertarikan terhadap biologi kemudian masuk menjadi mahasiswa di jurusan pendidikan biologi.

Banyaknya siswa SMA sebagai generasi muda yang belum mengenal lingkungan sekitarnya menjadi fokus utama kegiatan ini. Hal tersebut karena dengan mengenal mahkluk hidup yang ada disekitarnya, maka rasa kepedulian akan sedikit demi sedikit tumbuh dan berkembang. Pembelajaran yang sedikit sekali porsinya dilapangan menjadi salah satu penyebabnya sehingga dengan kegiatan PPM ini harapannya siswa akan memiliki alternatif kegiatan wisata yang juga merupakan kegiatan pembelajaran.

Program pengabdian masyarakat ini akan diadakan dalam dua pertemuan yaitu pertemuan pertama untuk pembelajaran burung dan habitatnya, lalu pertemuan kedua pelatihan pengamatan burung dan pembelajaran lapangan untuk pengamatan langsung dikampus FMIPA UNY. Harapannya siswa akan memiliki pemahaman yang menyeluruh tentang burung dan habitatnya.

\section{HASIL DAN DISKUSI}

Dari 30 siswa yang terlibat kegiatan PPM ini dibagi menjadi 5 kelompok. Pembagian kelompok dilakukan secara acak dan berdasar pada jumlah pos pengamatan sebagai lokasi dengan frekuensi keteramatan burung yang cukup tinggi. Lokasi pengamatannya adalah, laboratorium FMIPA, Kebun Biologi, Dekanat FMIPA, taman Ormawa FMIPA, Ruang U.

Kelima kelompok mendapatkan hasil pengamatan dengan dilengkapi gambar sketsa burung. Kelompok yang paling banyak mendapatkan amatan burung adalah kelompok 2 dengan lokasi pengamatan di kebon Biologi. Kelompok tersebut berhasil mengamati 7 jenis burung.

Setelah proses pengamatan burung dilapangan selesai, kemudian 30 siswa tersebut memberikan respon dan tanggapan tentang kegiatan PPM ini dan saran tentang perbaikan apa yang harus dilakukan agar kegiatan PPM ini dapat dilanjutkan di kemudian hari.

Dari hasil setiap aspek penilaian, semua aspek menunjukan nilai lebih dari 3. Artinya kegiatan pembelajaran lapangan pengamatan burung kampus sebagai salah satu alternatif wisata pendidikan dapat diterima dengan baik oleh siswa SMA

Dapat diasumsikan bahwa siswa mengapresisasi kegiatan ini sebagai bentuk cara baru dalam belajar tentang lingkungan terutama tentang nilai penting burung dalam sebuah ekosistem. Kegiatan pengamatan burung langsung pada objeknya dilapangan menjadi proses pembelajaran karena didalamnya juga disampaikan tentang kehidupan burung dan habitatnya serta peran dan fungsi keberadaan burung dalam 
menjamin siklus kehidupan dalam ekosistem di kampus.

Tabel. 1 Hasil pengamatan dari masing masing kelompok

\begin{tabular}{|c|c|c|}
\hline No & Kelompok / Lokasi & Hasil Pengamatan \\
\hline \multirow[t]{6}{*}{1} & Kelompok 1, & 1. Trenon vernans \\
\hline & lokasi laboratorium & 2. Streptopelia chinensis \\
\hline & & 3. Aegithina tiphia \\
\hline & & 4. Pygnonotus goiavier \\
\hline & & 5. Pygnonotus aurigaster \\
\hline & & 6. Lonchura maja \\
\hline \multirow[t]{7}{*}{2} & Kelompok 2, & 1. Trenon vernans \\
\hline & Lokasi kebun bio & 2. Streptopelia chinensis \\
\hline & & 3. Aegithina tiphia \\
\hline & & 4. Pygnonotus goiavier \\
\hline & & 5. Pygnonotus aurigaster \\
\hline & & 6. Riphidura javanica \\
\hline & & 7. Dicaeum trochileum \\
\hline \multirow[t]{4}{*}{3} & Kelompok 3, & 1. Passer montanus \\
\hline & Lokasi dekanat & 2. Pygnonotus goiavier \\
\hline & & 3. Pygnonotus aurigaster \\
\hline & & 4. Lonchura maja \\
\hline \multirow[t]{3}{*}{4} & Kelompok 4, & 1. Pygnonotus goiavier \\
\hline & Lokasi ormawa FMIPA & 2. Pygnonotus aurigaster \\
\hline & & 3. Passer montanus \\
\hline \multirow[t]{5}{*}{5} & Kelompok 5, & 1. Aegithina tiphia \\
\hline & Lokasi ruang $\mathrm{U}$ & 2. Pygnonotus goiavier \\
\hline & & 3. Pygnonotus aurigaster \\
\hline & & 4. Riphidura javanica \\
\hline & & 5. Passer montanus \\
\hline
\end{tabular}

Burung pemakan biji atau buah yang secara tidak langsung juga sebagai pemencar benih tumbuhan. Burung pemakan serangga yang secara tidak langsung juga berperan sebagai pengendali serangga ataupun fungsi lain dari keberadaan burung sebagai salah satu bagian dari komponen penyusun ekosistem.

Kegiatan seperti pengamatan burung dan pengamatan objek biologi lainnya dapat menjadi sebuah paket wisata pendidikan yang menarik dan sangat bermanfaat. Pengamatan capung atau kupu-kupu di kampus FMIPA UNY dapat menjadi paket wisata pendidikan berbasis ekosistem kampus. Harapannya ekosistem kampus menjadi tempat berlangsungnya pendidikan lingkungan dengan berbasis pada ekosistem kampus sehingga pembangunan kampus dapat menyesuaikan dengan ekosistem yang sudah ada. Hal tersebut lebih kepada upaya perlindungan ekosistem alami sebagai tempat belajar agar tidak terganggu oleh pembangunan kampus.

Pada tanggapan/respon tentang kegiatan PPM, dari pertanyaan terbuka mendapatkan respon sebagai berikut :

1. Respon kemanfaatan kegiatan, mendapatkan $100 \%$. Artinya semua peserta kegiatan menyatakan bahwa kegiatan ini sangat bermanfaat, dan memberikan pemahaman terbaru. Metode belajar dengan cara seperti ini sangat menyenangkan.

2. Respon ketertarikan melakukan pengamatan burung di lokasi lain, mendapatkan $70 \%$. Artinya $70 \%$ dari semua peserta menyatakan tertarik untuk 
melakukan pengamatan burung dilokasi lainnya. Seperti Sekolah, Kaliurang, UGM, Kebun binatang.

3. Respon tentang ketertarikan melakukan pengamatan objek biologi lainnya mendapatkan $83 \%$. Artinya $83 \%$ peserta kegiatan ini tertarik untuk melakukan pengamatan objek biologi lainnya, seperti capung, kupu atau tumbuhan.

4. Respon tentang kritik dan saran mendapat $50 \%$. Artinya ada sebagian yang memberikan kritik dan saran untuk memperbaiki kegiatan PPM ini, sedang sebagian lagi tidak memberikan saran dan merasa kegiatan ini sudah cukup baik.

\section{KESIMPULAN}

1. Siswa sudah diberikan pelatihan tentang pengamatan burung dan sebagian besar merasa tertarik untuk terus melakukan pengamatan burung ataupun objek biologi lainnya.

2. Siswa sudah terlatih dalam menggunakan panduan lapangan elektronik dan merasakan kemudahan dalam melakukan proses identifikasi.

3. Burung yang berhasil diidentifikasi oleh sebuah kelompok dengan menggunakan panduan lapangan elektronik, paling banyak 7 jenis burung.

\section{UCAPAN TERIMA KASIH}

Penulis mengucapkan banyak terima kasih kepada mahasiswa kelompok pengamat burung Bionic juga pengurus Himpunan Mahasiswa Biologi yang turut membantu lancarnya kegiatan ini dan juga terwujudnya harapan.

\section{PUSTAKA}

Tabur, Mehmet Ali. Ayvas, Yusuf. (2010). Ecological Importance of Birds. ISSD 2010 science book p560-p565. 2nd International Symposium on Sustainable Development. June 8-9 2010, Sarajevo.

Cagan H. Sekercioglu, Gretchen C. Daily, and Paul R. Ehrlich. (2004). Ecosystem consequences of bird declines. 1804218047, doi: 10.1073/pnas.0408049101. Proceeding of the National Academy of Science of the United States of America. 